\title{
Student Experiences in a Structural Engineering Course: Responses of Viola- tion and Grief When a Novice Instructor Implements Project-Based Learning
}

\section{Ms. Jillian Seniuk Cicek, University of Manitoba}

Jillian Seniuk Cicek is a PhD Candidate in Engineering Education in the Department of Biosystems Engineering, Faculty of Engineering at the University of Manitoba, in Winnipeg, Canada. She is a research assistant for the Centre for Engineering Professional Practice and Engineering Education in the Faculty of Engineering. Her research areas include outcomes-based teaching and assessment, and student-centered instruction. She is involved in the University of Manitoba Faculty of Engineering's curriculum improvement process.

Dr. Marcia R Friesen P.Eng., University of Manitoba

Prof. Sandra Ingram, University of Manitoba

Sandra Ingram, Ph.D., is a SSHRC award-winning scholar and Associate professor in Design Engineering, Associate Chair (NSERC Design Engineering) and adjunct professor in Biosystems Engineering at the University of Manitoba in Winnipeg, Canada. Dr. Ingram is responsible for teaching the technical communication course in the faculty as well as an integrated approach to communications in the Biosystems Engineering department. Her research interests include professional skills in engineering, internationally educated engineers, co-operative education programs, women in engineering, and post-graduate training of engineers

Dr. Douglas Warren Ruth 
Student Experiences in a Structural Engineering Course: Responses of Violation and Grief When a Novice Instructor Implements Project-Based Learning 


\section{Student Experiences in a Structural Engineering Course: Responses of Violation and Grief When a Novice Instructor Implements Project-Based Learning}

\section{Introduction \& Objectives}

In the Faculty of Engineering at the University of Manitoba, Canada, a novice instructor with more than a decade of industry experience in consulting engineering practice re-designed a third-year structural engineering design course around a projectbased instructional method. The impetus for changing the course was twofold: his own industry experience that drove his desire to educate students with the engineering knowledge and skills, and foster in them the engineering mind-set to succeed in industry; as well as the fact that the structural course that he was charged with teaching had remained largely the same as when he was a student a decade prior.

The course had been traditionally taught in a lecture-tutorial format. Discrete elements of structural design were introduced in lectures and demonstrated by example, and students completed assignments and tutorial work to practice self-contained problems. A written mid-term exam and final exam rounded out the evaluation scheme, with exams focused on solving separate problems of structural design details. No over-arching course project or connections between assignments were devised.

For the new course, the instructor provided students with architectural drawings of a three-story mixed-occupancy building. He created assignments for the course that required students to design steel components within the building, including columns, beams, connections, floor decks and roof. The final project was student teams' design of a canopy to be added to the building. The course still consisted of the tri-weekly lecture and weekly tutorial format, with weekly assignments, tutorials, a mid-term and final exam, which students were responsible for individually. However, the lectures, assignments and tutorials were all intended as components of the final project.

The instructor's enthusiasm and energy for the project-based design of his course led him to want to explore students' experiences and perceptions, and their attainment of the targeted learning objectives. To that end, two engineering education researchers planned and carried out an intrinsic case study of the Winter 2013 offering of the course. After executing the study, the researchers were surprised to find quite a negative bent in students' responses to the course in the data. They recognized that students' expectations and perceived experiences were quite different from the instructor's expectations and intended experiences for his students. Therefore, the study was extended for a second year.

The objective of the broader study, within which this work is positioned, was to be a formative assessment tool for the course to explore students' retrospective experiences and perceptions of their participation in a structural engineering course designed using project-based learning, in the anticipation of analyzing the data for findings related to 
student learning outcomes, specifically professionalism. The following overarching research questions guided the study:

How do students experience and perceive the application of a project-based learning approach to a structural engineering course? In what capacity did students meet the instructor's educational learning objectives, specifically professionalism, in the course?

In this paper, we report on the findings from the first year of the study (Winter 2013), with specific focus on our research question regarding students' perceptions and experiences of the course, relative to the motivations, perspectives and expectations of the instructor. The analysis is further guided by the question that has emerged from the data: How do students' expectations of the course align with their experiences? The findings are explored through the frameworks of Expectancy Violation Theory and the steps of trauma and grief, as well as within the context of issues identified with implementing student centered-instruction (SCI) methods such as project-based learning. The redesigned structural course, the remaining quantitative data, and the third research question regarding the attainment of the instructor's educational learning objectives will be presented in a future paper.

\section{Background: Student-Centered Instruction}

Properly administered student-centered instruction (SCI), such as active learning, cooperative learning and project-based learning, has been found to promote high-level problem-solving, critical and creative thinking skills, deep learning and improved knowledge retention, more so than the more traditional pedagogical practice of lecturing ${ }^{1,2}$. SCI has been shown to increase student interest and engagement in engineering ${ }^{3}$, and support the development of students' communication and teamwork skills ${ }^{4}$. It can also enhance students' intrapersonal skills by promoting self-efficacy, character building, and resilience ${ }^{5}$. All of these traits are commonly cited desired attributes of a global engineer working in a multi-disciplinary world, and are reflected in engineering accreditation requirements today ${ }^{6-8}$.

Project-based learning in particular can simulate an industry-like environment for students, to facilitate the development of the skills required for practicing professional engineers. In project-based learning, students are formally instructed to ensure they have the foundation of knowledge needed to work on and complete the project assigned ${ }^{9,10}$. Emphasis is given to the final product ${ }^{9}$ and on incorporating and using the knowledge that students have already acquired ${ }^{10}$. The final project can be a design, model, device or computer simulation, and the summative assessment is usually a report or presentation detailing the finished product ${ }^{10}$. It is by nature multi-disciplinary, and builds the transferability of skills from one context to another ${ }^{11}$.

Despite the benefits of SCI activities including project-based learning, efforts to use SCI are often met with resistance by students ${ }^{2-4,12}$. This resistance may be due to the violation of the educational norms students expect, such as a large, lecture-based classroom or minimal student participation ${ }^{13}$. Students may be asked to engage at a level that is foreign or unnerving for them; they may be surrounded by courses where a more 
traditional pedagogy is dominant ${ }^{13,14}$. SCI requires that students monitor and take more responsibility for their own thinking and learning, and they may not feel ready or willing to do $\mathrm{so}^{3,15}$.

Students' reactions, both positive and negative, to an educational setting have been interpreted using Expectancy Violation Theory (EVT). EVT postulates that individuals have predetermined assumptions or expectations regarding situations that they are participants in, as well as presuppositions about how others in those situations will behave $^{13}$. If those presumptions are not met, their expectations are violated ${ }^{13}$. Students' expectations are formed by their previous experiences, by "cultural norms and contextual cues" "13 as well as by what they have heard from others about individuals' behaviors in specific circumstances. Students in a third year engineering program will have defined expectations about how their institution's courses are taught, and will have learned from other students details and opinions about classes they are enrolled in and the instructors who will teach them. Whether or not these expectations are conscious or subconscious, they will be in place, and consequently, students can struggle with circumstances that go against them. A less traditional instructional strategy that is unanticipated or that goes against the norm that they have thus far experienced, may cause students to feel that their expectations are being violated, and their reaction, which may be either positive or negative, in turn affects the success of the chosen method ${ }^{3,13}$. Indeed, "When students' expectancies are negatively violated, the violation can have negative implications for how students view the class and the instructor" ${ }^{\prime \prime}$. Expectations are so important to how a student functions in a learning situation, that "..the extent to which they are met affect students' satisfaction, motivation, and perhaps even their ability to learn"13. It is recommended in the research that due to the importance of expectancy on students' learning, the power of violating students' expectations be taken into consideration when designing a course ${ }^{13}$.

Students' responses may also be explained vis-a-vis steps of trauma or grief, as "Woods (1994) observes that students forced to take major responsibility for their own learning go through some or all of the steps psychologists associate with trauma and grief"2. These steps include 1. shock; 2. denial; 3. strong emotion; 4. resistance and withdrawal; 5. surrender and acceptance; 6 . struggle and exploration; 7. return of confidence; and 8 . integration and success ${ }^{2}$. Students may experience a gamut of emotions and behaviors from questioning the instructional strategy and thereby the instructor, to complaining to an authority figure, to grudgingly trying to participate in the class, to finally achieving a sense of confidence and acceptance ${ }^{2}$. These potential reactions increase the complexity of understanding and interpreting students' responses to SCI.

To further complicate matters, there are classic issues that can arise when instructors implement SCI, which likely will exacerbate and increase student resistance. These include perceived ambiguous learning objectives; perceived unclear or unfair assessments; perceived excessive demand on student time that may or may not be disproportionate to the educational objectives, and which can be discouraging and stressful; and provocation of oppositions in engagement, where simultaneously, in the same class, some students are experiencing very high engagement and motivation, and others very low ${ }^{15}$. Instructors may not be aware of the confusion, anxiety, resentment or resistance that may rise due to 
these factors, and "... what students actually experience or perceive may by different than what is intended by faculty.",

To navigate these issues, continual and constructive feedback to students is a critical component in the effective use of $\mathrm{SCI}^{16}$. Feedback guides students through SCI in a number of ways: instructors can employ feedback to assess the current understandings of students, identify misconceptions, encourage strengths, lessen students' mental load, support metacognition, and nudge students in new directions ${ }^{5}$. Importantly, "feedback allows for comparisons between a desired educational outcome and actual student performance", which allows for instructors and students to be cognizant about where students are in their thinking and understanding, and where they are going.

Employing SCI in any course is a complex undertaking ${ }^{17}$, and in engineering, where lecture methods traditionally reign, it may be fraught with more complications than an instructor might expect, particularly if the instructor is new to teaching ${ }^{4,18}$.

\section{Methodology}

The study was planned as an intrinsic case study, intended as an in-depth exploration of one bounded system - a third year structural engineering course - chosen based on interest rather than representative of a particular phenomenon ${ }^{19,20}$. We designed the research protocol to use purposeful sampling, in which potential participants are identified and approached to request their participation, based on their ability to contribute to the goals of the study. Data were collected from students once the course was complete using several qualitative methods: an anonymous on-line open-ended survey, a semi-structured focus group interview, individual interviews with students, the instructor and teaching assistants, and document analysis of student course work. The instructor was also asked to communicate his learning objectives in written form, and we took anecdotal field notes during our initial meetings when we discussed the possibility and implementation of the study. Two consecutive cohorts of students $(\mathrm{N}=80$ per cohort) were invited to participate from two course offerings: Winter 2013 and Winter 2014. Ethics approval was procured from our institution's Research Ethics Board.

The student survey was designed to be open-ended, exploring students' expectations and actual experiences in the course relative to knowledge, skills, and attitudinal outcomes, learning tasks, and class structure as a project-based course. The survey consisted of 20 questions for all participants, with an additional six questions for students who had previously taken the course. Questions asked students about their expectations when they began the course and their perceptions in regards to their experiences in the course, their development of professionalism, and their knowledge/skill retention.

Examples include:

When you started the course, what did you expect to learn?

When you started the course, what kind of work did you expect to do?

Now that you have finished the course, did the content match what you expected?

Now that you have finished the course, did you learn the skills that you expected?

What if anything, was the most surprising aspect of the course? 
What if anything, was the most interesting aspect of the course?

If someone asked you what you learned in the course, how would you respond?

An increasing emphasis in the engineering curriculum is to assist students to develop

the knowledge, skills, and attitudes of a professional engineer. This can mean

different things to different people. Do you think the course help you develop your professionalism?

What will you take away from this course into the future?

The survey was offered to students before the focus group interview, to allow the interview protocol to be shaped by the survey data and enable researchers to further explore the questions and emerging themes that arose. Questions for the interview conducted with a participant from the Winter 2013 cohort included:

There is a sense from the survey responses that students had heard about this course before they took it. How much do you think this affects students' expectations of a course and/or of an instructor?

Were your expectations (learning, skills, professionalism, other expectations) met in this course?

There was a sense from the survey responses that perhaps the assignments were not what students expected. Can you comment on this?

There seems to be a polarity of survey responses between expectations that were matched and expectations that weren't; and a polarity between responses that were very positive and responses that were very negative. Can you comment on this? There was a sense of surprise and frustration in regards to the group project. Can you comment on this?

The instructor approached this class using project-based learning. His objectives were to have students develop a complete understanding of the scientific aspect of structural steel design (i.e. material science, load calculations, understanding the building and design codes and structural analysis and design), as well as to have students develop an ability to recognize a problem, analyze a problem in multiple ways, develop multiple solutions, understand the construction process, and understand the economical and ethical aspects of the process. Do you think these objectives were met?

The limitations of the survey ( $\mathrm{n}=17$ in first cohort and $\mathrm{n}=22$ in second cohort), interview ( $n=1$ in first cohort and $n=2$ in second cohort) and focus group ( $n=0$ in first cohort and $n=3$ in second cohort) collection methods were the small number of student participants in each, and the extremity of the student responses, which indicated that selfselection bias was a potential factor in the data ${ }^{21}$. In order to gather more data and lend credibility to findings we derived, we opted to continue the study for a second year.

Data were examined using a constant comparative thematic analysis, which was applied to a holistic exploration of the case. One researcher completed the analysis, which was then reviewed by the second researcher to corroborate the credibility and confirmability of the findings ${ }^{22}$. Participants were sent an aggregate summary of the survey data, interview transcriptions and the summary of the themes, and invited to 
substantiate the findings as a form of member checking, increasing the trustworthiness of the study ${ }^{22}$.

In this paper, we report on the findings from the first year of this study (Winter 2013), and purposely focus on the motivations, perspectives and expectations of the instructor garnered from his written educational objectives and anecdotal conversations regarding the course and the study, relative to the insights gleaned from the perspectives, expectations and experiences of the students from the survey and interview data. We also focus on the relationship between what students described experiencing throughout the course and what they anticipated experiencing within the context of implementing SCI. This approach, as confirmed in the research by Gaffney et al. (2010), is essential in determining the factors for efficacious applications of student-centered learning methods, which have been shown to result in significant student learning ${ }^{13}$. Data were interpreted through the frameworks of Expectancy Violation Theory, the steps of trauma and grief, and issues identified with implementing SCI.

\section{Findings}

\section{Instructor's Objectives and Expectations}

The instructor, having spent his first ten years as a professional engineer in industry before moving to academia, held the philosophy that this third year structural engineering course should prepare students to become professional industry engineers. This informed the design of the course. He wanted "...to ensure that the students will be able to work on an actual project and put together a cohesive design from the individual components that they learn." He felt that this would reflect the real-life expectations for graduate engineers and make their education immediate, up-to-date and authentic, stating “...design of a complete structure during the course would make their education relative right when they are learning it. There would be no questions as in 'how and where will I ever use this information?" He spoke of the students gaining a "solid understanding" of "real engineering," which included recognizing and analyzing problems in multiple ways; developing multiple and practical solutions and choosing the best one; thinking about the construction process of a proposed structural system; and understanding economical and ethical responsibilities when designing a structural system.

\section{Students' Expectations}

The majority of participants expected to learn general engineering design for steel structures; about a third expected to learn structural and steel design theory. A number of participants expected to learn how to use the CISC Handbook of Steel Construction. Quite a few students expected the course to be based on the prerequisite course. There were a number of general expectations of students that touched on similar topics to the instructor, although in a broader way, such as general design procedures, methodology and application for approaching and solving problems, structural stability, changes in structures due to time or materials, leadership and engineering judgment. There were other expectations that were unique, such as a "tour of a building in progress." Then there were general academic expectations, including workloads described in comparison to previous 
courses, "Expected smaller work load"; "[Expected] Clear expectations established by the professor"; and "[Expected] Practical questions that helped us use the procedure outlined in class."

\section{Students' Perceived Experiences Versus Expectations}

About half of students generally felt that the knowledge and skills they experienced in the course matched what they had expected to learn. The interview participant, who had trepidations about the project due to expectations informed by peers, said "...my expectations were slightly exceeded because the project was improved." However, there were also experiences that differed from expectations, expressed by the majority of the participants. For example, there were a number of comments regarding students' perception that they were not explicitly taught to use the CISC Handbook of Steel Construction: "code interpretation left to us," and of perceived lack of other expected content: "Design philosophy and methodology lacking"; "content unclear; topics confusing"; "no logical order" and "I learned much less than I'd hoped." Students commented on the difficulty of the instructor's expectations, which they perceived were not aligned with their expectations: "Expected basic knowledge and assignments, not things engineers are expected to do 10 years down the road."

The interview participant, as discussed, whose expectations were based on what was known about the course from the previous year, while being relieved that the project wasn't quite as demanding as expected, experienced the assigning of the project as a stressful situation: "We didn't know [when the project] was coming, that was the problem. Has he cancelled it? And then he dumps it on us. And we're like nooooo, nooooo." Although this participant felt the assignments were similar to other structural assignments, the participant did speak about the disconnection between lectures and assignments that went against the general expectations of students: “...the assignments were just problems that were not actually very similar to the examples he'd even done during the notes... He didn't connect it very well." The participant spoke about how the project was due during exam period, which was misaligned with previous student experiences, and thereby expectations: "I'm of the very firm opinion that course time is for course work and exam period is for exam work. If you want to have something due during exam period, if it's more than just a tiny assignment, it should be clearly stated at the beginning of the course, so that you can have some kind of work around, not slapped on in the last three weeks of the course. We don't have that much experience getting dumped with a big project."

\section{Expectancy Violation}

When students' expectancy is violated by their experiences in the course, they either react in a positive or negative way to the course and/or to the instructor ${ }^{13}$. Our findings showed a majority of reactions during the first year of the study were negative; only a few participants had positive reports of their course experience. One positive comment was: "The actual design of the building was very interesting." The interview participant, as discussed, had "a very negative set of expectations" going into the course. Therefore, when those expectations were violated, the response was more positive: "The project they had to do the year before I heard was far too big and his expectations were unreasonable 
given that they were in other design-based classes. Fortunately that didn't turn out to be so bad this year." Negative reactions from participants included: "How awful the whole experience was: long assignments, vague instructions, the midterm, rude professor"; "How terrified I was for the final exam"; "How much I hated the course"; "Never take a class with this professor again."

\section{Steps of Trauma and Grief}

Findings in the data showed that participants' perceived experiences and subsequent sense-making of them could be viewed through the framework of trauma and grief stages. For example, participants' comments indicated:

1. Shock: “...the ruthlessness of the professor asking students to leave their comfort zone..."

2. Denial: "Should be an elective [course]."

3. Strong emotion: "The course makes me question if I should be an engineer."

4. Resistance and withdrawal: "[I] Will never become a structural engineer because of this course."

5. Surrender and acceptance: "Potentially great prof. Needs to teach through examples more."

6. Struggle and exploration: "Tried to be positive. Degraded after the midterm. Around the finals, my attitude was one of hard work and determination."

7. Return of confidence: "Course took a long time and was very stressful, but in the end it worked out."

8. Integration and success: "When I design, I imagine how to solve the problem and imagine the connections. I look at structures everywhere and imagine how they were built."

Findings showed that more participants made comments that fit into the first four stages of trauma and grief, compared to the latter four stages.

\section{Issues with SCI implementation}

Themes that emerged from the data on participants' experiences in the course also showed that issues associated with implementing SCI were evident, including perceived ambiguous objectives, unclear and unfair assessments, and imbalanced workload for the course. There was also evidence of polarities in students' engagement, and frustration with perceived lack of feedback. As discussed previously, the negative interpretations that participants assigned to their experiences can be traced back to a violation of expectations. 


\section{Perceived Ambiguous Objectives}

Data from students displayed themes of perceptions of a lack of direction and connection between content, coursework and exams. Comments included "No logical order for content"; "Assignments vague in scope and direction"; "Concepts confusing due to lack of connections, explanations and directions." The interview participant said, "A lot of the assignments were based on that building we were supposed to be working on. But we weren't explicitly told that that was the project."

\section{Perceived Unclear and Unfair Assessments}

Frustration surrounding the midterm exam emerged in the data. Participants stated that there was "One cumulative question, and it was difficult to do well." They perceived "Harsh marking." Students also questioned how assessments were conducted, stating "Many students didn't finish or failed; yet ended up with an 'A'." The interview participant said, "...the assignments overwhelming, the project assigned too late", and commented on the content of the exams: "Design should not be tested in a test situation, that's why we have projects. Design is a creative and iterative process and it doesn't work well if you've got half an hour and people under exam stress."

\section{Perceived Disproportion Between Time Given, Coursework Required and Value of Assignments}

Another theme that emerged was perceptions that the coursework was too heavy and the assignments too long. Participants stated, "Assignments tedious: repetition excessive, not beneficial to learning", and experienced that the "workload was excessive." The interview participant spoke to this theme: “...we got over-assigned...assignments and tutorials are worth 10 percent of your final mark and you get an assignment every single week and a tutorial every single week and the tutorials are really long and like assignments..." The interview participant went further to explain how the marks given to the assignments were not worth the effort in the larger scheme of the course, which undermined the perceived value of the work: “...this assignment is worth .5 percent of my final mark, do I want to spend an extra hour getting 20 percent higher on it?... No, because that's not worth anything to me... Both the students and TAs were overloaded with this stuff. And so it lost most of its value."

\section{Polarities in Students' Engagement}

Findings showed that there were extremes in students' responses to the course and the instructor, both in terms of motivation and engagement. Statements that demonstrate this include: "...the professor cared about the quality of engineers that his class produced..." compared to "Doesn't seem to enjoy teaching or want students to succeed"; and "I liked this course; am interested in steel design" versus "Steel design interesting; wish I'd learned more about it"; and "Very challenging and interesting" compared to "Unnecessarily challenging." This polarity was also evident in student responses when asked what they learned in the course. Responses ranged from positive, "Analysis techniques will help me in the future as an engineer" to negative: "Nothing"; "How not to 
become a design engineer"; and "How to perform better despite frustration and anger." When students were asked to describe their attitude towards the course, responses ranged from "Fairly positive" and "Necessary" to "Disappointed" and "Hated it." The interview participant stated, "There's always going to be people who like the class and people who don't like the class. But it's not always this polarized." This participant rationalized the polarity of the responses in this way: "I think I can explain it a little bit. He was a very good prof for structural people. But they were a minority of the class. If you were interested in the subject and already had a good understanding of the background, this could be a really fantastic course. He could have been an interesting prof if you were into it. It would have been great. But we're not all structural people. There's environmental, there's transportation, water resources, geo-tech and if you aren't interested it was horrible, horrible."

\section{Perceived Lack of Feedback}

Perceived lack of feedback was a main theme that emerged from the data. The majority of participants experienced feedback as sparse and vague, so students could not use it to inform the next assignment, which produced a "shot in the dark" approach to presenting solutions. One participant stated, "Lack of feedback was disappointing." Students perceived that teaching assistants had excessive amounts of marking for the course, with little time in which to do it, which resulted in unsatisfactory feedback: "TAs seemed confused, couldn't give helpful feedback due to excessive amount of marking..." and "...marking difficult due to length of assignments." The interview participant said, "...we get [the assignment] back and of course it's not marked well because two TA's, eighty students, two assignments a week...I never found out if I was doing it right or not. It was poor feedback..." The interview participant spoke about not seeing the completed project, because it was due during exam week, which meant the group members worked on it separately, dependent on their exam schedules: "Well I never even saw the completed project... I finished it all and just gave it to one of them so that they could put it together during exam week...I couldn't point out that project because I never saw it." The interview participant also stated that there was no feedback given to students after the project was handed in: "I have no idea what I got on that project, none at all."

\section{Discussion}

Data highlight that the objectives of the instructor were very specific, and could be likened to the higher-order knowledge, skills and behaviors one might associate with being a practicing structural engineer in the field. This is understandable as that was the instructor's philosophy for the course - to foster industry-ready, professional engineers and it was constructively aligned with his choice to use project-based learning. The instructor had the insight to ascertain that students learn more deeply from authentic situations ${ }^{9}$.

However, due to the fact that this was a third year course, with students only half way through their engineering education, it could be considered that these objectives were too lofty for third year students who had little or no exposure to courses with curricula developed entirely around a project. Also, if the instructor did not provide clear 
explanations, acknowledge the differences in his approach from traditional undergraduate teaching in engineering, or present his motivations for choosing such an approach, students would not have had the chance to realign their expectations. It is not hard to recognize that students might have different expectations for this course, with it being the first fully project-based and first design course many of them had taken, and with the course following on the heels of another required structural engineering course taught in a traditional lecture-tutorial style. This mismatch of expectations between the instructor and students can be seen in the data. Students' expectations were far more general in nature, perhaps characteristic of their understanding and experiences in their lives thus far as students, and of their experiences in the prior structural analysis course. Generally, they anticipated this course to function much like the prerequisite course in terms of content, workload, assignments/projects/exams and time commitment. Clearly, from the onset of this course, there was a misalignment between the instructor and students' expectations. Consequently, it is not surprising that students' expectations of the course were, for the most part, not what they perceived they would experience, and their reactions to the course and to the instructor demonstrated this discord.

Students' experiences led to extremes in reactions to the course and to the instructor from angry resistance to a mildly more accepting, and even somewhat protective attitude. Findings support the literature on student resistance to SCI, and can be viewed within the framework of Expectancy Violation Theory. Through this theoretical framework, students whose expectations are violated (for example, in this case the amount of coursework was perceived as unexpected and difficult to manage) can react negatively toward the learning experience and toward the instructor himself ${ }^{13}$. Conversely, students whose expectations in the learning environment are either met or better than they anticipated can report more positively regarding their learning in the course and involvement with the instructor ${ }^{13}$. The polarity of responses from participants in our study demonstrates this. There were far more dramatically negative comments aimed at both the course and the instructor. The positive responses were fewer, and were characterized by a tone either slightly protective of the instructor despite the perceived difficulties, or by a sense of students finding success after surviving a traumatic experience. These responses fit into the theoretical framework of Expectancy Violation Theory.

The data from participants also indicated that their reactions to their experiences in the course could be characterized as stages of trauma and grief, from shock and denial to acceptance and even success. Findings for the first year of the study showed that more comments reflected the initial stages rather than the latter. It is not unusual for students to experience all or some of these stages when faced with the overriding responsibility for their education, and some believe it is a journey students must take to achieve autonomy in their learning ${ }^{2}$. The wide range of possible emotional responses that students can experience underscores the complexity of implementing SCI in the classroom.

Adding to these complications are the classic issues that have been found when employing SCI: issues that cause student stress ${ }^{17}$, and which are evidenced in our data. These include the potential for perceived ambiguous learning objectives, unclear or unfair assessments, disproportionate course load to the given time, and polarities in engagement. In order for SCI to be successful, students need to be coached ${ }^{2,5}$, and there should be 
constructive alignment between educational objectives and course activities to support students' progression through project-based learning ${ }^{16,24}$. Otherwise, students may recognize that they can earn the same or better grades with less effort in a course with traditional delivery ${ }^{13}$. This perception, along with students' belief that they learn as well or better in the latter format ${ }^{3}$, could derail an instructor's efforts to use SCI.

Another key insight in our findings was the critical role of feedback when executing SCI. Feedback is a fundamental aspect when learning a new skill ${ }^{2}$, and can be omitted or lacking in SCI if there is the mistaken perception that students learn better and more deeply by doing it on their own ${ }^{23}$. Feedback between students and instructors should be continuous and constructive ${ }^{15,18}$. Additionally, instructors should have the opportunity and would benefit from receiving their own feedback by conversing with colleagues about their SCI activities ${ }^{18}$.

Overall, these findings cannot be separated from the fact that the instructor was a novice instructor who had limited knowledge of the pedagogy behind project-based learning, despite his deep subject matter expertise in structural engineering. Some experts flag SCI methods such as problem-based learning as more suitable for faculty members with extensive teaching experience, due to the student resistance that is bound to arise ${ }^{4}$. Others recommend a more informal "easing" into SCI strategies, mixing activities with more traditional approaches; and many stress that instructors who are planning to implement SCI should be knowledgeable of the research in the area ${ }^{18}$. On the other hand, when a novice instructor is willing to take on such a complex educational challenge for the benefit of learners, their efforts should be supported, particularly when the research clearly demonstrates "...that properly implemented SCI leads to increased motivation to learn, greater retention of knowledge, deeper understanding, and more positive attitudes toward the subject being taught" 2 . This speaks to the importance of faculty having a keen understanding of the pedagogy and research behind SCI to help instructors instill its practices. This is especially important as "Available evidence indicates that the uptake of research-based strategies is somewhat limited and that when faculty do attempt to implement a strategy they often modify the strategy in ways that are less consistent with what research suggests is ideal for student learning",25. Comprehension of sound, researchbased pedagogical methodologies and faculty support are vital for all instructors, regardless of whether they have a strong foundation in the content and industry knowledge of an engineering area.

\section{Conclusions}

The student resistance evidenced in the findings of our study, while a surprise for the instructor and the researchers, is shown in the literature as a common response to using SCI in the classroom. Instructor and students' expectations coming into a course are likely to differ; when faced with a violation of expectations, student responses can range from support to hostility, dependent on earlier learning experiences and present circumstances. Students exposed to SCI, especially for the first time, may undergo some or all of the stages of trauma and grief. These responses are natural. What will assist instructors in negotiating these reactions, particularly novice instructors with limited teaching experience, is a firm grounding in the pedagogy and research regarding student-centered 
learning techniques, and support from colleagues and the faculty. This will help circumvent the issues surrounding the implementation of SCI activities, and encourage instructors with the understanding that they are not alone in what they are experiencing. More importantly, this will help instructors support and coach their students, as students shoulder the responsibility of their own learning, and navigate the muddy waters of SCI. Despite the negative student responses in this study, the extensive literature on SCI supports the efficacy of it for deep learning, student engagement and retention, and the development of a broad range of technical and professional skills. These far-reaching and long-lasting benefits are the impetus to navigate the natural responses to expectancy violation, as well as the provocation to promote a culture of faculty development in teaching strategies connected to the research on student-centered learning.

\section{References}

1. Felder, R. M. 2011. Hang in there! Dealing with student resistance to learner-centered teaching. Chem. Engr. Education, 45(2): 131-132. http://www4.ncsu.edu/unity/lockers/users/f/felder/public/StudentCentered.html (2015/01/25).

2. Felder, R. M. and Brent, R. 1996. Navigating the bumpy road to student centered instruction. College Teaching, 44(2): 43-47. http://www4.ncsu.edu/unity/lockers/users/f/felder/public/Student-Centered.html $(2015 / 01 / 25)$.

3. Borrego, M.J., Prince, M.J., Shekhar, P., Waters, C. and Finelli, C. J. 2014. Student perceptions of instructional change in engineering courses: A pilot study. In $121^{\text {st }}$ ASEE Annual Conference and Exposition: 360 Degrees of Engineering Education. Indianapolis, IN. June 15-18. http://www.asee.org/search/proceedings (2015/01/15).

4. Felder, R. M., Brent, R. and Prince, M. J. 2014. Engineering instructional development: Programs, best practices and recommendations. In Cambridge Handbook of Engineering Education Research, eds. A. Johri and B. M. Olds, 409-436. New York, NY: Cambridge University Press.

5. Hirshfield, L. Whinnery, J. L., Gilbuena, D. M. and Koretsky, M. 2014. A study of feedback provided to student teams engaged in open-ended projects. In $121^{\text {st }}$ ASEE Annual Conference and Exposition: 360 Degrees of Engineering Education. Indianapolis, IN. June 15-18. http://www.asee.org/search/proceedings (2015/01/15).

6. Litzinger, J.A., L. R. Lattuca, R. G. Hadgraft and W. C. Newstetter. 2011. Engineering education and the development of expertise. Journal of Engineering Education, 100(1): 123-150.

7. Smith, K. A., S. D. Sheppard, D. W. Johnson, and R. T. Johnson. 2005. Pedagogies of engagement: Classroom-based practices. Journal of Engineering Education, 94(1): 87-101.

8. Passow, H. 2012. Which ABET competencies do engineering graduates find most important in their work? Journal of Engineering Education, 101(1): 95-118.

9. Yadav, A., D. Subedi, M. A. Lundeberg and C. F. Bunting. 2011. Problem-based learning: Influence on students' learning in an electrical engineering course. Journal of Engineering Education 100(2): 253-280.

10. Prince, M. J. and R. M. Felder. 2006. Inductive teaching and learning methods: Definitions, comparisons, and research bases. Journal of Engineering Education 95(2): 123-138. 
11. Dym, C.L., Agogino, A.M., Eris, O., Frey, D.D. and Leifer, L.J. 2005. Engineering design thinking, teaching, and learning. Journal of Engineering Education, 94(1): 103-120.

12. Litzinger, T. A. and Lattuca, L. R. 2014. Translating research to widespread practice in engineering education. In Cambridge Handbook of Engineering Education Research, eds. A. Johri and B. M. Olds, 375392. New York, NY: Cambridge University Press.

13. Gaffney, J. D. H., Housley Gaffney, A. L. and Beichner, R. J. 2010. Do they see it coming? Using expectancy violation to gauge the success of pedagogical reforms. Phys. Rev. ST Phys. Educ. Res. 6, 010102. http://journals.aps.org/prstper/abstract/10.1103/PhysRevSTPER.6.010102\#fulltext (2015/01/25).

14. Lattuca, L. R. and Litzinger, T. A. 2014. Studying teaching and learning in undergraduate engineering programs: Conceptual frameworks to guide research on practice. In Cambridge Handbook of Engineering Education Research, eds. A. Johri and B. M. Olds, 477-496. New York, NY: Cambridge University Press.

15. Davis, C. and Yadav, A. 2014. Case studies in engineering. In Cambridge Handbook of Engineering Education Research, eds. A. Johri and B. M. Olds, 161-180. New York, NY: Cambridge University Press.

16. Daly, S. R., Finelli, C. J., Al-Khafaji, A. B. and Neubauer, M.J. 2012. Student perspectives of faculty classroom practices. In $119^{\text {th }}$ ASEE Annual Conference and Exposition: Spurring Big Ideas in Education. San Antonio, TX. June 10-13. http://www.asee.org/search/proceedings (2015/01/15).

17. Kolmos, A. and de Graaff, E. 2014. Problem-based and project-based learning in engineering education: Merging models. In Cambridge Handbook of Engineering Education Research, eds. A. Johri and B. M. Olds, 141-160. New York, NY: Cambridge University Press.

18. Akili, W. 2014. On implementation of classroom-based pedagogies of engagement: Relevant measures and general outcomes. In $121^{\text {st }}$ ASEE Annual Conference and Exposition: 360 Degrees of Engineering Education. Indianapolis, IN. June 15-18. http://www.asee.org/search/proceedings (2015/01/15).

19. Creswell, J. W. 2013. Qualitative inquiry and research design: Choosing among five approaches, 3rd ed. L.A., CA: Sage.

20. van Note Chism, N., E. Douglas and W. J. Hilson, Jr. 2008. Qualitative research basics: A guide for engineering educators, Rigorous Research in Engineering Education: Creating a Community of Practice, National Science Foundation, U.S.A., Report Number DUE-0341127.

21. Olsen, R. 2008. Self-Selection Bias. In Encyclopedia of Survey Research Methods, ed., P. J. Lavrakas. Sage Research Methods. http://srmo.sagepub.com/view/encyclopedia-of-survey-research-methods/n526.xml (2015/01/27).

22. Leyden, J.A., B. M. Moskal and M. Pavelich. 2004. Qualitative methods used in the assessment of engineering education. Journal of Engineering Education, 93(1): 65-72.

23. Kirschner, P. A. 2006. Why minimal guidance during instruction does not work: An analysis of the failure of constructivist, discovery, problem-based, experiential, and inquiry-based teaching. Educational Psychologist, 41(2): 75-86.

24. Gijbels, D., F. Dochy, P. Van den Bossche and M. Segers. 2005. Effects of problem-based learning: A meta-analysis from the angle of assessment. Review of Educational Research, 75(1): 27-61. http://arno.unimaas.nl/show.cgi?fid=15855 (2012/12/11).

25. Dancy, M. H. and C. Hendersen. 2012. Experiences of new faculty implementing research-based instructional strategies. In AAPT 2011 Physics Education Research Conference. Melville, NY. http://homepages.wmich.edu/ chenders/Publications/2011DancyPERCPaper.pdf (2015/01/27). 